Campos Neutrais - Revista Latino-Americana de Relações Internacionais Vol. 1, No 3, p. 88-106, Setembro- Dezembro de 2019

\title{
Escândalos políticos de corrupção e socialização política dos jovens no Sul do Brasil
}

\author{
Ana Julia Bonzanini Bernardi \\ Henrique Souza da Silva** \\ Jennifer Azambuja de Morais ${ }^{* * *}$
}

Resumo: Os escândalos políticos de corrupção tiveram grande protagonismo no Brasil nos últimos anos, principalmente com os desdobramentos da Operação Lava-Jato e o processo de Impeachment da então presidente Dilma Rousseff. Nesse cenário, objetivou-se analisar a relação entre o clima de corrupção política e a formação do tipo de cultura política dos jovens da região Sul do país, que, em sua compreensão, e, majoritariamente, assinalaram a corrupção como principal problema do país. Para tanto, foram utilizados dados de pesquisa realizada pelo NUPESAL/UFRGS, entre 2015 e 2016, nas três capitais da região Sul, quais sejam, Porto Alegre, Florianópolis e Curitiba, com jovens de 13 a 24 anos, de escolas públicas e privadas de ensino médio. As análises preliminares permitem a interpretação de que os jovens internalizaram fortemente a relação campo político-corrupção, apresentando atitudes e comportamentos hostis em relação às instituições políticas.

Palavras-chave: Escândalos de corrupção, jovens, socialização política.

\section{Political corruption scandals and political socialization of young people in southern Brazil}

\begin{abstract}
Political scandals of corruption have played a major role in Brazil in recent years, especially with the developments of Operation Lava-Jato and the impeachment of the former President Dilma Rousseff. In this scenario, the objective of this paper is to analyze the relationship between the climate of political corruption and the formation of the type of political culture among Young people in the southern region of the country, witch, pointed out corruption as the main problem of the country. In order to do so, we use data from a survey conducted by NUPESAL / UFRGS, between 2015 and 2016, in the three capitals of the southern region, namely Porto Alegre, Florianópolis and Curitiba, with youngsters from 13 to 24 old, from public and private high school students. Our preliminary findings, show that

\footnotetext{
* Doutoranda do Programa de Pós-Graduação em Ciência Política pela Universidade Federal do Rio Grande do Sul

** Graduando em Ciências Sociais pela Universidade Federal do Rio Grande do Sul.

*** Professora do Departamento de Ciência Política da Universidade Federal do Rio Grande do Sul. Pós-doutora em Ciência Política pela Universidade Federal do Rio Grande do Sul.
} 
young people have strongly internalized the political-corruption field relationship, presenting hostile attitudes and behaviors towards political institutions.

Keywords: Corruption scandals, youth, political socialization.

\section{Introdução}

No Brasil, o cenário atual está marcado pela ampla midiatização de escândalos políticos de corrupção, principalmente os da Lava-Jato, que servem de fundo para as crises política, social e econômica vivenciadas desde as eleições presidenciais de 2014.Esse clima de intranquilidade, contribuiu para ressaltar os sentimentos de insatisfação e desconfiança com as instituições políticas, revelando uma conjuntura de insegurança generalizada com a situação do país e de incerteza com estabilidade do sistema democrático (BAQUERO; MORAIS, 2018).

Estes sentimentos contribuem para a manutenção de uma cultura política de resignação, marcada pelo descontentamento não só com as instituições políticas, como com o regime político. Principalmente, entre os jovens, que estão iniciando com suas primeiras experiências na política e internalizando seus valores, crenças, atitudes e comportamentos políticos.

Neste processo de socialização política, os meios de comunicação apresentam um papel fundamental como agente socializador, ao fazerem uma ampla cobertura dos escândalos políticos. Para Lattman-Weltman (2003), não se pode negar que a mídia é hoje a instituição mais decisiva para a qualidade do exercício da cidadania no Brasil pós ditadura de 64, uma vez que esta impõe coordenadas e linguagens específicas sobre as estratégias dos políticos para as disputas eleitorais; fornece os principais elementos simbólicos e cognitivos para a escolha do eleitor; forja - conscientemente ou não, deliberadamente ou não - consensos sobre a pauta política e institucional, e assim, define, de certa forma a agenda pública, dos seus termos mais gerais a alguns dos mais específicos (LATTMAN-WELTMAN, 2003).

A partir deste contexto objetivamos analisar a relação entre o clima de corrupção política e a formação do tipo de cultura política dos jovens da região Sul do país, visto que a maioria destes, 58,8\%, indicam a corrupção como principal problema do país. Para tanto, foram utilizados dados de pesquisa realizada pelo NUPESAL/UFRGS, entre 2015 e 2016, nas três capitais da região Sul, quais sejam, Porto Alegre, Florianópolis e Curitiba, com jovens de 13 a 24 anos, de escolas públicas e privadas de ensino médio. 
Campos Neutrais - Revista Latino-Americana de Relações Internacionais

Vol. 1, No 3, p. 88-106, Setembro- Dezembro de 2019

\section{Socialização Política}

A constituição de atitudes e comportamentos políticos é o resultado das vivências dos indivíduos com a dimensão cultural da sociedade, através da socialização. Em um sentido amplo, a socialização política é o processo de transmissão de valores e expectativas da cultura política existente na sociedade ${ }^{1}$. Os estudos seminais sobre esse tema, datados dos anos de 1950 e 1960, como de Hyman (1959), Hess e Torney (1967), Easton e Dennis (1969) e Dawson e Prewitt (1969), são marcados pela análise de socialização infantil e influência da família. A partir dos anos de 1970, com Jennings e Niemi (1974), começaram a analisar a socialização de adolescentes e adultos, bem como se identificaram outros agentes socializadores além da família.

Nos estudos que destacavam a importância da socialização infantil, sugeriam que essa seria a etapa decisiva para a constituição de atitudes políticas dos indivíduos (EASTON e DENNIS, 1969). Os estudos de Percheron (1971) e Almond e Powell (1972) enfatizaram que a socialização política não ocorre somente na infância, mas sim por toda vida. Tal perspectiva ganhou mais relevância com as obras de Jennings e Niemi (1974) e uma coletânea de Sigel (1989), postulando que a socialização política seria um processo permanente, através das experiências que o indivíduo teve ao longo de sua vida.

A socialização política passou também a ser vista com o desenvolvimento cognitivo (PIAGET, 1977; VIGOTSKY, 1996) e com a educação cívica do sujeito (NIEMI e HEPBURN, 1995). Vigotsky (1996) argumentava que no seu desenvolvimento cognitivo, os indivíduos sofrem a influência do meio histórico e social. Piaget (1977), por sua vez, salienta a evolução por estágios no desenvolvimento cognitivo do sujeito. Já a educação cívica é um mecanismo de difusão sistemática de conhecimento sobre o governo e os assuntos públicos, visto que não há reprodução automática de atitudes e valores democráticos (NIEMI e HEPBURN, 1995).

Na Ciência Política, Easton e Dennis (1969) destacam que não basta ter uma teoria da socialização política, é necessária uma teoria política da socialização política, capaz de analisar a esfera partidária e a estabilidade sistêmica, ou seja, que vincula a socialização política com a manutenção do sistema. Tal perspectiva é voltada para as consequências da socialização política para o sistema político como um todo. E esta perspectiva adotada na tese utiliza o conceito de socialização política focalizada nos indivíduos em particular e como internalizam valores, normas e crenças na constituição de uma cultura política juvenil.

\footnotetext{
${ }^{1}$ Almond e Powell (1972) definem socialização política como o processo pelo qual as culturas políticas são mantidas ou transformadas.
} 
Neste processo de socialização política a transmissão de atitudes políticas, segundo Almond e Coleman (1969), pode ocorrer de forma latente ou manifesta. A socialização latente ocorre quando a transmissão de atitudes e orientações políticas é feita de maneira difusa e não programada, tanto pela família como pelas demais instituições. Já a socialização manifesta ocorre quando a transmissão é explícita, feita pelas agências diversas de socialização 2 (família, escola, igreja, ambiente de trabalho, meios de comunicação, partidos políticos e pares). Almondet al. (2008) destacam três aspectos da socialização política: o primeiro, como a socialização pode ocorrer (latente ou manifesta); o segundo, a socialização é um processo constante de experiências que impactam nas atitudes políticas, que impactam mais na juventude; e, terceiro, os padrões de socialização provocam unificações ou divisões na cultura política de uma sociedade.

Nas pesquisas sobre socialização no Brasil (BAQUERO, 1997; SCHMIDT, 2001; NAZZARI, 2005; BAQUERO e BAQUERO, 2007; BAQUERO e CUNHA, 2010; ROBALLO, 2011; LUCAS, 2003; SILVEIRA e AMORIM, 2005), os autores destacam que a socialização infantil é essencial para constituição de atitudes políticas, mas que as experiências cotidianas também podem afetar as atitudes por toda vida do indivíduo. Tais pesquisas constataram que uma parcela significativa dos jovens brasileiros não simpatiza com nenhum partido político, não possui interesse na política, não participa e não confia de forma geral nas instituições políticas. Keil (2004) afirma que grande parte do desinteresse pelo campo político, atualmente, está na ausência ou inadequação da socialização política da criança e do jovem pela família, escola e partido político, o que impacta na ausência de valores políticos durante a formação do jovem brasileiro. O que para Baquero (2011, s/p), em uma sociedade, como a brasileira, que é caracterizada por desigualdades sociais e políticas, "o processo de formação de atitudes políticas tende a se manifestar de forma incongruente, produzindo uma cultura política híbrida".

O conceito de socialização política ajuda a compreender a ligação entre juventude e política, considerando que é uma fase preparatória para vida política e de desenvolvimento das capacidades e atitudes que podem estimular a constituição de uma cultura política participativa. É necessário considerar nesse processo a cultura política existente no Brasil, pois a transmissão de valores políticos depende também da história e do contexto cultural do país.

\footnotetext{
${ }^{2}$ O estudo brasileiro de Schmidt (2000 e 2001) demonstra que as principais agências socializadoras são: família, escola e mídia.
} 
Campos Neutrais - Revista Latino-Americana de Relações Internacionais Vol. 1, No 3, p. 88-106, Setembro- Dezembro de 2019

\section{Escândalos Políticos}

O Brasil, nas últimas duas décadas, tem presenciado o florescimento/surgimento de uma série de escândalos de natureza política em seu cotidiano. Por exemplo, o Mensalão (2006), marcou o "início" desse período que se estende até hoje. O último expoente está sendo a Operação Lava-Jato, deflagrada em 2014 e em curso até o presente momento. Outro acontecimento político, que como veremos, se constituiu em escândalo político foi o processo de Impeachment da ex-presidente Dilma Rousseff. A quantidade de notícias publicadas e televisionadas é um aspecto que liga todos esses eventos.

Diversos estudos são realizados no Brasil sobre a questão (ALDÉ; VASCONCELLOS, 2008; AZEVEDO, 2010; CHAIA; TEIXEIRA, 2001; FERES JÚNIOR; SASSARA, 2016). Algumas teorias que partem da área da comunicação, como a Teoria de Agendamento e a de Enquadramento de notícias, se propõem em analisar o fenômeno do escândalo político a partir da estrutura sequencial, elementos narrativos, de estilística e de personificação presentes no corpo da noticia. Em outros, são feitas contagens sobre o número de material noticiado em determinados veículos de comunicação, como forma de delimitar a quantidade de assuntos com maior divulgação e captar o sentido por trás das manchetes e reportagens. Nesse artigo, porém, foi objetivado analisar a relação entre os escândalos políticos de corrupção com a socialização políticas de jovens do Sul do Brasil, a partir do ponto de vista da Cultura Política.

Antes, para fins de tornar claro o debate sobre o tema, é necessária uma maior reflexãoa respeito do fenômeno escândalo e como ele atinge a esfera política; o que se entende por corrupção, e, sobretudo, como a Operação Lava-Jato e o Impeachment de Dilma Rousseff constituem um fenômeno dessa natureza. Um escândalo pode ser de natureza sexual, de corrupção, de abuso de poder, artístico ou sobre diversos outros temas que se pode mensurar. O que ele implica, nessa ordem, é uma alegada transgressão, não necessariamente verdadeira, mas uma publicização de tal transgressão que gera uma resposta negativa por parte do público. O escândalo deve ser suficientemente sério para gerar uma desaprovação ou aversão àqueles que veem de fora o acontecido. Do contrário, não se tornará um escândalo (ADUT, 2008; THOMPSON, 2002). Outra característica também pertinente ao escândalo é o caráter episódico que ele assume, sendo transmitido em esquemas sequenciais e não de modo isolado. Assim, a lógica de dramatização, storytelling e atratividade são aspectos buscados pelas mídias que os produzem (EKSTRÖM; JOHANSSON, 2008).

Tais características são comuns aos escândalos de menores proporções, tanto quanto aos que assumem uma maior escala. Como o conhecemos hoje, o escândalo midiático, é uma 
consequência do próprio modus operandi dos meios de comunicação, que se materializaram como um meio a partir da criação da imprensa - final do século XV - com o surgimento do rádio - fim do século XIX - e com o aparecimento da televisão, em meados de 1940. Assim, pode-se dizer que o escândalo é um produto dos meios de comunicação.

Mais recentemente, com o consumo e popularização da internet, o escândalo ganhou novas proporções. Como bem aponta Tumber e Waisbord (2004), o advento de novas mídias potencializa o aparecimento de novos escândalos devido ao modo como operam e pela rapidez e diminuição das distâncias com quais as mensagens são propagadas (CASTELLS, 2012). O ambiente em rede (CASTELLS, 2005) cria a possiblidade de geração de conteúdo a todo instante, não necessariamente com uma lógica fechada de programação, como são em veículos mais tradicionais - também ampliando os produtores de informação, uma vez que todos podes produzir conteúdo informativo, mesmo que não sejam veículos midiáticos. Outro efeito também assinalado, é que devido à grande escala de informações produzidas muitas informações disponibilização não contam com uma checagem prévia, potencializando fenômenos como as fake news, produzindo desinformação (ALLCOTT; GENKWOLVITZ, 2017).

Na obraOnScandal, Adut (2008), cita dois fatores que direcionam as atitudes e comportamentos durante o escândalo: 1.a contaminação que o escândalo causa quando publicizado e 2.as provocações que podem partir do indivíduo acusado/ transgressor. $\mathrm{O}$ alcance desses dois aspectos varia positivamente em relação ao status do indivíduo envolvido no caso; nesse sentido, as elites seriam mais vulneráveis à escândalos, uma vez que "the grater the discrepancybetween the moral claimsembodiedby the offender and the actthatispublicized, the bigger the scandalis" (ADUT, 2008, p. 24).

A contaminação se relaciona ao fato de que pessoas associadas ao acusado seriam, com alguma frequência, associadas por meras alegações, ou até mesmo "por tabela". O mesmo se estende a organizações ou coletividade ligadas ao acusado; surgindo a natureza coletivista do escândalo. Já na provocação, o ator envolvido no escândalo, desafiado pelas acusações, desafiaria o público por meio de atos, gestos ou falas, como forma de inserir mais um ator em cena.

O escândalo de natureza político, além da óbvia característica de estar inserido dentro do campo político, coloca em xeque a reputação e o exercício do poder político do agente envolvido. A reputação, como capital simbólico nos termos de Bordieu (2001), é imprescindível nas interações e articulações dentro do subcampo político e no campo político mais amplo. Assim, um escândalo político tem força potencial de destruir a reputação não só 
Campos Neutrais - Revista Latino-Americana de Relações Internacionais Vol. 1, No 3, p. 88-106, Setembro- Dezembro de 2019

de uma figura política, mas de todo um grupo ligado a ela - uma vez o caráter coletivista do escândalo não afeta apenas o agente, mas também o partido e os valores que ele e tal instituição sustentam. Seu acontecimento efetivo depende da gravidade e da credibilidade da denúncia, e acusações mais comuns a esse campo dizem respeito ao uso indevido do cargo público para benefício privado, abuso de poder e traição (ADUT, 2008; BOURDIEU, 2001; THOMPSON, 2002).

Em The PoliticsofScandal, Markovits e Silverstein (1988) consideram que a característica chave para se compreender o escândalo político não está tanto no status dos atores envolvidos, como Adut (2008) dá ênfase, mas na natureza dessa transgressão: a violação dos processos devidos legais. Entendidos como as Leis, a Constituição e todo aparato burocrático que restringe o abuso de poder do ator político, tais processos, segundo os autores, seriam característica de excelência de democracias liberais, onde, por sua vez, o escândalo encontraria lugar fértil para ocorrer. Nessa perspectiva, os escândalos, como conhecemos, ficariam restritos à esse tipo de regime, não acontecendo em outros modelos políticos.

a característica crítica de todo escândalo político não é o grau de proveito pessoal envolvido nem é o mérito normativo dos fins procurados, mas é a presença de qualquer atividade que procure aumentar o poder político às expensas dos processos e procedimentos adequados(MARKOVITS; SILVERSTEIN apud THOMPSON, 2002, p. 124)

Já para Thompson (2002) e Adut (2008), os escândalos remontam a épocas como a França de Luís XVI, a Inglaterra Vitoriana e mesmo a Moscou de Stalin, onde acusações e confissões públicas eram importantes para o regime. Assim, não constituiriam acontecimentos restritos aos dias de hoje, muito menos à regimes em específico.

A despeito do que se tome como característica exata do ato político de transgressão, os últimos escândalos desse campo no Brasil foram majoritariamente ligados ao que está tão presente no imaginário brasileiro, quanto no discurso produzido pela mídia: a corrupção. A corrupção, em seu significado mais básico, pode ser entendida como o uso indevido de um poder delegado para ganho próprio; no seu sentido dentro a administração pública, o uso indevido da função pública para benefício privado (FILGUEIRAS, 2004; FILGUEIRAS, 2009; RIBEIRO, 2000). Para Warren (2005), a corrupção é, sobretudo, uma forma dupla de desigualdade política no processo de tomada de decisão, na medida em que deixa o outro de 
fora dessa escolha, e, ao excluí-lo, delibera sobre assuntos que podem o afetar. Também assinala que a corrupção é um problema de agência que se configura na assimetria de informações entre o principal e o agente, devido ao fato de o último possuir mais dado e informações sobre a tarefa que o foi delegado.

Para além de definir o conceito, outros estudos na área se voltam para questão de como mensurar a corrupção, e, a partir dela, analisar suas causas e seus efeitos. O problema que se impõe, de cara, é o de como mensurar algo, que, quando bem-sucedida, não pode ser verificado na realidade. Assim, observar o fenômeno a partir de seu noticiamento nos meios de comunicação ou de condenações contabilizadas na esfera penal constituíram alguns dos esforços nesse sentido. A maneira que vem sendo adotada recentemente é a de mensurar o fenômeno a partir da percepção de especialistas e pessoas em geral, como o Índice de Percepção da Corrupção (IPCorr) (SPECK, 2000). Já em Klitgaard (1994), a questão chave seria a de entender o problema do ponto de vista das deficiências estruturais de informação e incentivos para o surgimento da corrupção.

Tentando oferecer soluções e formas de combater o problema, Silva (2005) orienta para práticas de accontability, para além de sua noção vertical, orientada para sua aplicação horizontal, e para uma agenda de pesquisa nacional que tenha como objeto mecanismos desse tipo. Assim, a importância do aprofundamento da estrutura democrática, em formas de mecanismos de transparência, agências de supervisão onde o contato com a sociedade é maximizado e criação de Leis que modifiquem o sistema de incentivos, que influenciam a decisão ou não de tomar decisões privados em lugar de coletivas, constituiriam possíveis saídas. Como iremos observar, o mote que envolveu a alegação de Crime de Responsabilidade cometido por Dilma Rousseff se baseou na ideia de um abuso de poder, na medida em que ela "maquiaria" os resultados fiscais do governo para dar um "ar" de superávit às contas públicas. A Lava-Jato, por sua vez, constituiu claramente por parte dos funcionários públicos a extrapolação de suas funções para benefício próprio, e, por parte dos agentes privados, uma forma de extrair renda de bens públicos.

\section{A Lava-Jato e o impeachment}

A Operação Lava-Jato ${ }^{3}$, deflagrada em 2014, é um dos casos mais representativos de corrupção no setor público, se referindo à um esquema de lavagem e desvio de recursos

\footnotetext{
${ }^{3}$ Para se ter uma ideia de sua extensão, a Operação, até o momento em que se escreve este artigo: tem 60 fases deflagradas; cerca de dois (2) mil e quatrocentos (400) procedimentos instaurados; oitenta e duas (82) acusações criminosas contra 347 pessoas (sem nomes repetidos); duzentos e quarenta e duas (242) condenações contra
} 
Campos Neutrais - Revista Latino-Americana de Relações Internacionais Vol. 1, No 3, p. 88-106, Setembro- Dezembro de 2019

envolvendo a Petrobras, empreiteiras nacionais, partidos e atores políticos. Ela buscou investigar fraudes e recebimento de propina nas licitações envolvendo empresas prestadoras de serviços à Petrobras, crimes que se estenderam de empresários até políticos e seus respectivos partidos. Dentre seus principais personagens - que poderíamos dizer que conduziram o ritmo da investigação - estão o ex-diretor de Abastecimento da Petrobras, Paulo Roberto Costa, o doleiro Alberto Youssef, já com passado de envolvimento de corrupção no caso do Banestado, Nestor Cerveró, ex-diretor da área Internacional da Petrobras, Renato Duque, ex-diretor de Serviços e o hoje Ministro da Justiça e Segurança pública, Sergio Moro(MPF, 2019; EBC, 2019).

A primeiro publicização do caso aconteceu em 17/03/2014, quando a Polícia Federal realizou buscas e apreensões por Estados do Brasil e prendeu o doleiro Alberto Youssef, suspeito de comandar o esquema de movimentação e lavagem de dinheiro de pessoas físicas e jurídicas no mercado clandestino de câmbio. O nome da operação deriva do fato do grupo envolvido usar uma rede de lavandeira e postos de combustíveis para efetuar as transações. Logo após três dias, em 20/03, a PF prendeu o ex-diretor de Abastecimento da Petrobras, Paulo Roberto Costa, que já vinha sendo investigado pela compra de uma refinaria de petróleo norte-americana no Texas, sob acusação de destruição de provas que poderiam servir à Operação.

A partir desse ponto, o Operação começou a descobrir uma serie de ligações entre os doleiros e os ex-diretores com políticos, que também teria se beneficiado do esquema. Entre os primeiros envolvidos estão André Vargas, ex deputado federal pelo Partido dos Trabalhadores, o senador Fernando Collor de Melo, do Partido Trabalhista Brasileiro e Luiz Argôlo, deputado federal pelo partido Solidariedade. Em 14/11, em virtude de suspeita de formação de cartel entre empreiteiras prestadores de serviços à Petrobras, a PF cumpre mais alguns mandados de prisão, dessa vez em empresas como a Odebrecht, OAS e Camargo Corrêa. Entre novos desdobramentos e instalação de Comissão Parlamentar de Inquérito da Petrobras (26/02/2015), as investigações atingem Eduardo Cunha, político do Partido do movimento Democrático Brasileiro, e então presidente da Câmara dos deputados, por suposto envolvimento no esquema de corrupção. Após quase um ano, em 19/10/2016, já cassado, ele é preso preventivamente acusado de receber propina de contratos e usar contar no exterior para lavar o dinheiro (EBC, 2019).

cento e cinquenta e cinco (155) pessoas, sendo a maioria delas executadas na Justiça Comum2 e cerca de treze (13) bilhões de reais recuperados, de um montante, apontado pelo Conselho Administrativo da Petrobras, aproximado de oitenta e oito (88) bilhões perdidos por conta da corrupção (MPF, 2019). 
À luz da natureza coletivista dos escândalos políticos, as acusações e ligações rapidamente se espalharam pelos políticos e por seus respectivos partidos. Com a presença de provas ou não - quando apenas as acusações serviam para a prisão preventiva do agente envolvido - a Operação Lava-Jato se tornou um exemplo clássico de escândalo de corrupção, com o alto contingente de notícias e suposta desaprovação pública. Diferente do que ocorreu no processo de Impeachment de Dilma Rousseff, onde milhares de pessoas que desaprovavam a gestão da presidente e a consideravam corrupta ${ }^{3}$ foram às ruas, a Lava-Jato não incitou tal revolta, pelo menos não verificável em forma de manifestações ou protestos. Outra característica do escândalo explica esse fenômeno. Basta que o público se mantenha como espectador; se o público a qual a transgressão foi comunicada detêm ou não controle sobre o exercício de poder, é irrelevante (ADUT, 2008). A desaprovação, nesses casos, pode se constituir em desaprovação midiática, e não do público/receptor. A apresentação de notícias ou juízos negativos na imprensa pode se tornar autorreferente, traduzindo uma posição própria do meio de comunicação, distante daquela do público (THOMPSON, 2002).

Por outro lado, o componente de desaprovação pública esteve mais visível durante o processo de Impeachment de ex-presidente Dilma Rousseff (2015-2016). Em setembro de 2015, Dilma Rousseff foi acusada de Crime de Responsabilidade pelas chamadas "pedaladas fiscais", na premissa de que ela teria sido responsável por atrasar o repasse de verbas para bancos públicos ou privados intencionalmente, com intuito de apresentar resultados fiscais melhores sobre a situação econômica do país ${ }^{4}$. Nesse mesmo mês, a Câmara dos deputados acolheu o pedido, e em abril do ano seguinte (17/04/16), a votação determinou por dar encaminhamento ao processo, afastando Dilma do cargo por 180 dias.

O período que precedeu a abertura do processo foi marcado pelo grande número de manifestantes por todo o país, protestando em alto e bom tom para a saída de Dilma, contra o PT e o ex-presidente Lula, atribuindo à essa ala política a responsabilidade da crise econômica e a instauração da prática corrupta no Brasil. No dia 13/03/16, segundo a Policia Federal, cerca de 3,6 milhões de pessoas saíram às ruas pedido pelo Fora Dilma. Fato esse que foi amplamente divulgado e noticiado pelos veículos de comunicação de todo o país ${ }^{5}$. No dia 31 de agosto do mesmo ano, o Senado votou pelo afastamento definitivo de Dilma ao cargo, à condenando pelo crime de Responsabilidade Fiscal, mas não cassando seus direitos políticos.

Como mostrou Baptista (2015 e 2017) em trabalho recente, oscasos de corrupção transformados em escândalos -amplamentenoticiados pelas mídias, impactam na percepção de corrupção por parte das pessoas.Resta, agora, analisar essa percepção, verificada também em relação aos Jovens do Sul do Brasil, com a constituição de sua cultura política. 
Campos Neutrais - Revista Latino-Americana de Relações Internacionais

Vol. 1, No 3, p. 88-106, Setembro- Dezembro de 2019

\section{O impacto dos escândalos políticos de corrupção na constituição de uma cultura política juvenil}

Ao compreender socialização política como um processo pelo qual as culturas políticas são mantidas ou transformadas (ALMOND; POWELL, 1972), justifica-se a importância de analisar o processo de socialização política dos jovens no contexto atual de ampla midiatização dos escândalos políticos de corrupção, para, assim, verificar como a cultura política juvenil está se constituindo.

O papel de agente socializador dos meios de comunicação é importante, visto que estes estão agendando o debate da sociedade em torno dos escândalos de corrupção de políticos, de partidos e de governos. Este papel é ainda mais importante entre os jovens, que passam uma parte significativa de seu dia assistindo televisão, ouvindo rádio, lendo jornal ou revista e conectados na internet (MORAIS, 2017).

Podemos identificar o impacto da midiatização dos escândalos na opinião dos jovens pelos dados do Gráfico 1, pois 59\% dos jovens indicam a corrupção como principal problema do país.

Gráfico 1 -Principal problema do país (\%)

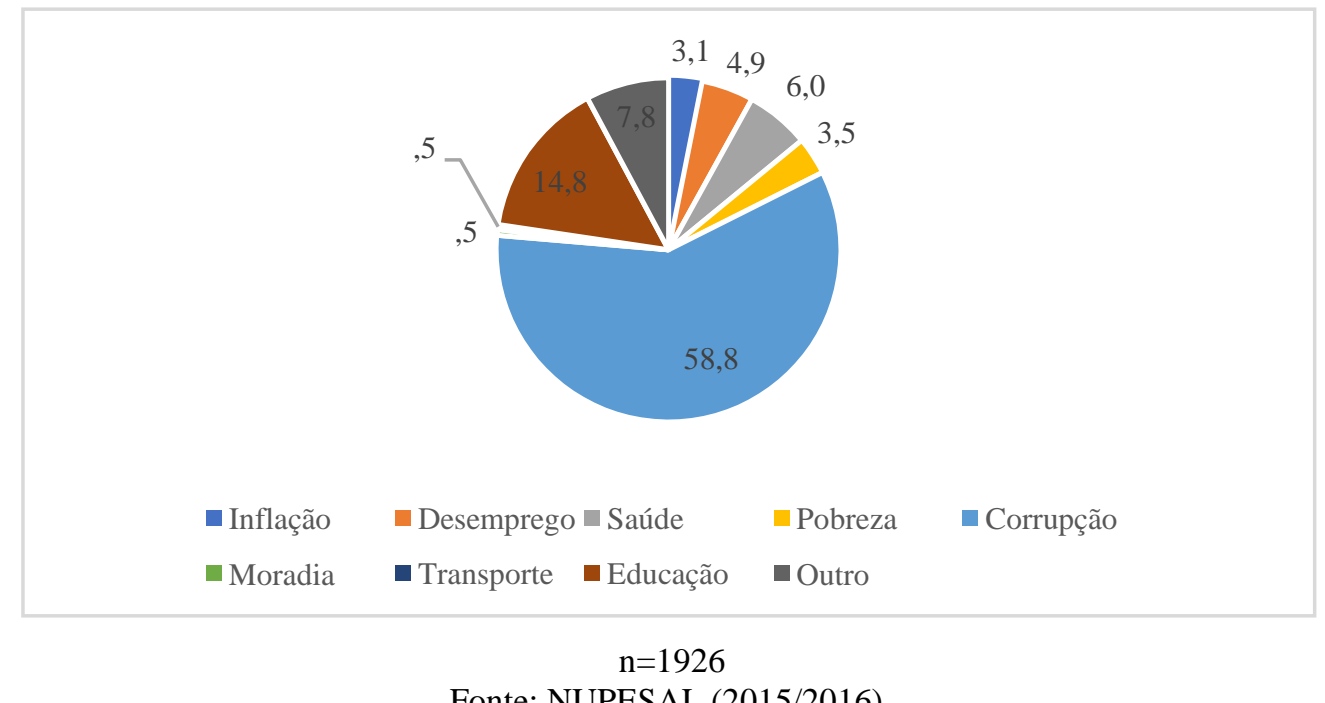

Fonte: NUPESAL (2015/2016).

A partir do momento em que a maioria dos jovens estudantes do Sul do país, tanto de escolas públicas e privadas, não indica fatores do seu cotidiano como principal problema do país (educação, saúde, desemprego, pobreza...), verifica-se que a midiatização dos escândalos políticos de corrupção, que é um fator mais distante do jovem, influencia no seu julgamento dos cenários econômico, social e político. 
Campos Neutrais - Revista Latino-Americana de Relações Internacionais Vol. 1, No 3, p. 88-106, Setembro- Dezembro de 2019

Partindo desta informação e para atingir o objetivo proposto de analisar a relação entre o clima de corrupção política e a formação do tipo de cultura política dos jovens da região Sul do país, primeiro se analisa a relação entre o principal problema do país (mantendo corrupção como uma categoria e agregando as demais opções em outra categoria) e o interesse por política (a categoria muito interesse).

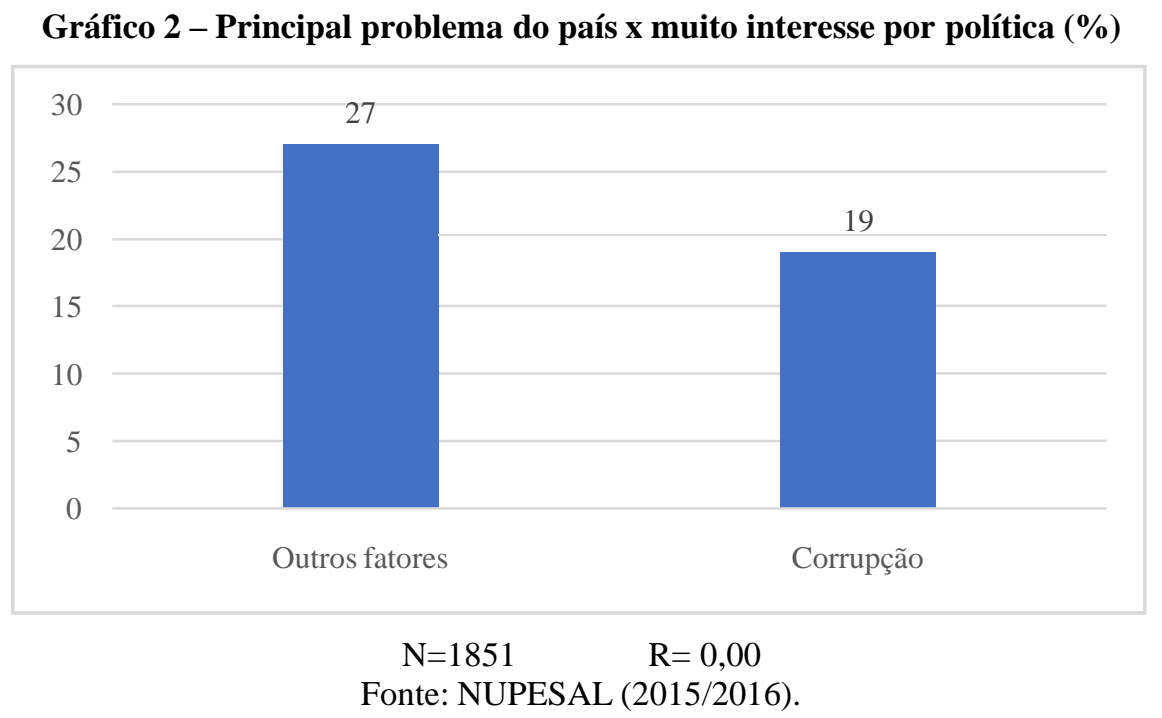

Os dados do gráfico acima indicam uma relação significativa entre o principal problema do país e o interesse dos jovens por política, percebe-se que os jovens que indicam a corrupção apresentam menos interesse, com 19\%, do que os jovens que indicam os demais fatores como principal problema, com 27\%. Ou seja, quando o jovem percebe que as instituições políticas, os políticos e o governo são ineficazes em resolver os problemas do país e também estão envolvidos em atos de corrupção, estes tendem a apresentar menos interesse pela política.

A partir desta relação, fez-se um filtro com os jovens que indicam a corrupção como principal problema do país (1132 jovens), fazendo uma análise do interesse por política com variáveis de cultura política, para então atingir o objetivo proposto neste trabalho.

Tabela 1 - Interesse por política x todos os políticos são corruptos (\%)

\begin{tabular}{l|l|l|l|l}
\hline & Concordo & Concordo em Parte & Discordo & Total \\
\hline Muito & 10 & 57 & 33 & 100 \\
\hline Pouco & 22 & 62 & 16 & 100 \\
\hline Nenhum interesse & 34 & 56 & 10 & 100 \\
\hline \multicolumn{5}{r}{$\begin{array}{r}n=1065 \\
r=0,00\end{array}$}
\end{tabular}

Fonte: NUPESAL (2015/2016). 
Campos Neutrais - Revista Latino-Americana de Relações Internacionais Vol. 1, No 3, p. 88-106, Setembro- Dezembro de 2019

Tabela 2 - Interesse por política x os políticos prometem, depois não cumprem (\%)

\begin{tabular}{|c|c|c|c|c|}
\hline & Concordo & Concordo em Parte & Discordo & Total \\
\hline Muito & 41 & 57 & 2 & 100 \\
\hline Pouco & 55 & 44 & 1 & 100 \\
\hline Nenhum interesse & 74 & 24 & 2 & 100 \\
\hline
\end{tabular}

Fonte: NUPESAL (2015/2016).

Tabela 3 - Interesse por política x não adianta participar da política, pois nunca muda nada

\begin{tabular}{l|l|l|l|l}
\hline & Concordo & Concordo em Parte & Discordo & Total \\
\hline Muito & 6 & 20 & 74 & 100 \\
\hline Pouco & 19 & 34 & 47 & 100 \\
\hline Nenhum interesse & 56 & 25 & 19 & 100 \\
\hline \multicolumn{7}{r}{$\mathrm{n}=1050$} \\
$\mathrm{r}=0,00$
\end{tabular}

Fonte: NUPESAL (2015/2016).

Como se pode observar nas três primeiras tabelas (1,2 e 3), os jovens que apresentam "Pouco" ou "Nenhum interesse" tendem a concordar com as colocações que conformam os políticos e a política num mesmo campo de descrença. Por outro lado, os que afirmam se interessar "Muito"tendem a discordar das afirmações; salvo na Tabela 2, onde a maior porcentagem (57\%) se encontra no "Concordo em Parte".

Tabela 4 - Interesse por política x participação em manifestações, protestos e passeatas (\%)

\begin{tabular}{l|l|l|l|l}
\hline & Participo & Já participei & Não participo & Total \\
\hline Muito & 28 & 40 & 32 & 100 \\
\hline Pouco & 9 & 33 & 58 & 100 \\
\hline Nenhum interesse & 12 & 32 & 56 & 100 \\
\hline \multicolumn{5}{r}{$\begin{array}{l}\mathrm{n}=1022 \\
\mathrm{r}=0,00\end{array}$}
\end{tabular}

Fonte: NUPESAL (2015/2016).

Quando se analisa a esfera da participação em manifestações, protestos e passeatas, aqueles que se interessam "Muito"afirmam que participam ou que já participaram mais do que aqueles com Pouco ou Nenhum interesse. O dado que talvez mais chame atenção éo alto percentual de "Não Participo" em todos os níveis de interesse. A inferência descritiva que pode ser feita é a de que entre os jovens que apontam e percebem a corrupção como principal problema do país, mesmo entre os que têm "muito" interesse, a não participação na esfera do 
Campos Neutrais - Revista Latino-Americana de Relações Internacionais Vol. 1, No 3, p. 88-106, Setembro- Dezembro de 2019

protesto é alta. Apesar de discordarem das afirmações homogeneizantes da política, na ordem prática, não se afastam daqueles que concordam.

Tabela 5 - Interesse por política x confiança nos partidos políticos (\%)

\begin{tabular}{l|l|l|l|l}
\hline & Confio & $\begin{array}{l}\text { Confio mais ou } \\
\text { menos }\end{array}$ & Não confio & Total \\
\hline Muito & 1 & 30 & 69 & 100 \\
\hline Pouco & 0 & 28 & 72 & 100 \\
\hline Nenhum interesse & 1 & 26 & 74 & 100 \\
\hline \multicolumn{4}{r}{$\begin{array}{l}n=0,00 \\
r=0\end{array}$}
\end{tabular}

Fonte: NUPESAL (2015/2016).

Tabela 6 - Interesse por política x confiança no judiciário (\%)

\begin{tabular}{l|l|l|l|l}
\hline & Confio & $\begin{array}{l}\text { Confio mais ou } \\
\text { menos }\end{array}$ & Não confio & Total \\
\hline Muito & 12 & 61 & 67 & 100 \\
\hline Pouco & 13 & 56 & 31 & 100 \\
\hline Nenhum interesse & 10 & 41 & 49 & 100 \\
\hline \multicolumn{5}{c}{$\begin{array}{l}\mathrm{n}=1042 \\
\mathrm{r}=0,00\end{array}$}
\end{tabular}

Fonte: NUPESAL (2015/2016).

Tabela 7 - Interesse por política x confiança no presidente (\%)

\begin{tabular}{|c|c|c|c|c|}
\hline & Confio & $\begin{array}{l}\text { Confio mais ou } \\
\text { menos }\end{array}$ & Não confio & Total \\
\hline Muito & 4 & 35 & 61 & 100 \\
\hline Pouco & 1 & 31 & 68 & 100 \\
\hline Nenhum interesse & 0 & 14 & 86 & 100 \\
\hline
\end{tabular}

Fonte: NUPESAL (2015/2016).

Das tabelas 5 a 7, a distinção possível observada em relação às atitudes não pode ser a mesma em relação à confiança nos partidos e no judiciário. Quando cruzados os níveis de interesse com a confiança nessas instituições, indiferentemente do interesse, majoritariamente os jovens confiam em parte ou não confiam nelas. Essa descrença corrobora com que alguns autores afirmam ser característicos do tipo de cultura político brasileira, marcada por baixos níveis de confiança, contribuindo para o individualismo, o florescimento da corrupção e relações clientelistas (AMORIM, 2006; MOISÉS, 1995; BAQUERO, 1997). 
Em relação ao judiciário, o nível de interesse tem um pouco mais de relevância em relação às outras instituições, mas não varia muito entre os que se interessam muito e os que de interessam pouco ou nada. Os partidos políticos, por sua vez, são a instituição com maior desconfiança (somados o "confia mais ou menos" com o "não confia"), independentemente do nível de interesse, em comparação à confiança ao presidente. O que chama atenção não é exatamente a existência de desconfiança, mas seu alto nível, que não se restringe a uma única instituição formal política, mas para ambas dela. (BAQUERO; MORAIS, 2018).

A percepção da corrupção também é um fator que impacta no nível de desconfiança. Quando entendida como algo generalizada, segundo Albertson e Gadarian (2015), cria nos cidadãos uma ansiedade política que afeta diretamente a maneira com que estabelecem redes de confiança e atitudes políticas. Tal incerteza e insegurança contribuem para o aumento nos níveis de desconfiança e apatia.

\section{Considerações finais}

Embora de maneira superficial e exploratória, podemos notar que existe uma percepção dos jovens sobre os casos de corrupção no país, e aqueles que atribuem os a corrupção como principal causa dos problemas no Brasil, tendem a repetir o mote da mídia de que todos os políticos são corruptos. Dentro dessa generalização, encontramos apoio na teoria dos escândalos políticos (THOMPSON, 2002), ao passo que a partir da midiatização da operação lava jato, toda uma categoria de políticos, mesmo que não envolvidos diretamente nos casos citados, passaram a ser percebidos pelos jovens como corruptos. Essa percepção também teve impacto na visão desses jovens sobre as instituições políticas, provocando um aumento de desconfiança nelas - mesmo aos que atribuem não ter interesse em política.

O quadro de insegurança sobre o futuro e desconfiança com as instituições e os políticos no geral, desemboca em uma apatia dentre as possíveis formas de participação e mobilização dos jovens para buscar mudanças políticas. Mesmo aqueles que declaram ter muito interesse em política, tem baixa participação. Esses fatores demonstram que os jovens, dentro de sua socialização política, vêm desenvolvendo o mesmo tipo de cultura política de seus pais e pares - que independente dos níveis de interesse, não conseguem tornar este interesse em prática política no dia a dia.

Embora não se possa fazer uma correlação direta entre a mídia e sua cobertura dos escândalos da lava jato com as respostas dos jovens no survey, acreditamos haver uma associação relevante entre estes fenômenos, levando em conta a teoria do contato. Assim, mesmo que o jovem não perceba a corrupção no seu dia a dia, ou talvez nem tenha a 
Campos Neutrais - Revista Latino-Americana de Relações Internacionais Vol. 1, No 3, p. 88-106, Setembro- Dezembro de 2019

compreensão total do fenômeno, a vê como o maior problema do país, uma vez que essa pauta vem sendo amplamente divulgada pela mídia como um discurso inequívoco e generalizado. Em pesquisas futuras, pretendemos aliar a analise qualitativa de falas dos jovens sobre corrupção, podendo desenvolver uma análise mais profunda destes fenômenos.

\section{Bibliografia}

ADUT, Ari. On scandal: Moral disturbances in society, politics, and art (Structural analysis in the social sciences). Cambridge, UK: Cambridge University Press, 2008.

ALBERTSON, B.: GADARIAN, S. K. 2015. Anxious Politics: Democratic Citizenship in a Threatening World. New York: Cambridge University Press, 2015.

ALDÉ, A.; VASCONCELLOS, F. Ao vivo, de Brasília: escândalo político, oportunismo midiático e circulação de notícias. Revista de Ciências Sociais, v. 39, n 2, p. 61-69, 2008.

ALLCOTT, Hunt; GENTZKOW, Matthew. Social Media and Fake News in the 2016 Election. JournalofEconomic Perspectives, Cambridge, MA, v. 31, n. 2, p. 211-236, 2017. Disponível em: $\langle\underline{\text { http://www.nber.org/papers/w23089.pdf }>\text {. Acesso em: } 2 \text { jul } 2019 .}$

ALMOND Gabriel; POWELL, G. Bingham; DANTON, Russell; STROM, Kaare. Comparative politics today: a world view. Pearson/Longman: Scott, Foresman and Company, 2008.

ALMOND, Gabriel; COLEMAN, James (org.). A política das áreas em desenvolvimento. Rio de Janeiro: F. Bastos, 1969.

ALMOND, Gabriel; POWELL, G. Bingham. Uma teoria de política comparada. Rio de Janeiro: Zahar. 1972.

AMORIM, Maria Salete Souza de. Cultura Política e Decisão Eleitoral no Oeste do Paraná. 253 f. Tese (Doutorado em Ciência Política) - Instituto de Filosofia e Ciências Humanas, UFRGS, 2006.

AZEVEDO, F. Corrupção, mídia e escândalos midiáticos no Brasil. Em debate, Belo Horizonte, v. 2, n 3, p. 14-19, 2010.

BAPTISTA, ÉRICA ANITA et al. Mídia e Escândalos Políticos: Efeitos sobre a percepção da corrupção. Revista Media e Jornalismo, Lisboa, v. 2, n. 1, p. 179-197, 2015.

BAPTISTA, Érica Anita. Corrupção e opinião pública: o escândalo da Lava Jato no governo Dilma Rousseff. (Tese de Doutorado). Programa de Pós-graduação em Ciência Política. Universidade Federal de Minas Gerais. 2017.

BAQUERO, Marcello. O papel dos adolescentes no processo de construção democrática no Brasil: um estudo preliminar de socialização política. Cadernos de Ciência Política, Porto Alegre, n. 8, p. 3-34, 1997. 
Campos Neutrais - Revista Latino-Americana de Relações Internacionais

Vol. 1, No 3, p. 88-106, Setembro- Dezembro de 2019

BAQUERO, Marcello. Padrões de constituição da Cultura Política na América Latina no Século XXI. In:

BAQUERO, Marcello. Cultura(s) política(s) e democracia no século XXI na América Latina. Porto Alegre:

Editora da UFRGS, 2011. p. 25-15.

BAQUERO, Marcello; BAQUERO, Rute. Educando para a democracia: valores democráticos partilhados por jovens porto-alegrenses. Ciências Sociais em Perspectiva, v. 6, p. 139-153, 2007.

BAQUERO, Marcello; CUNHA, Patrícia. A corrupção como limite à participação política juvenil: um estudo em democracias sul-americanas. In: BAQUERO, R.; NAZZARI, R. K. (orgs.). Formas de (ex) pressão juvenil e (in)visibilidade social. Cascavel: Coluna do Saber, 2010, p. 55-78.

BAQUERO, Marcelo; BERNARDI, Ana Julia. ; MORAIS, Jennifer A. Padrões emergentes de uma cultura política juvenil no sul do Brasil. Revista Eletrônica do Programa de Pós-Graduação da Câmara dos Deputados, v. 12 , p. $42-63,2019$

BOURDIEU, Pierre. O Poder Simbólico. Rio de Janeiro: Bertrand Brasil, 2001.

CHAIA, V.; TEIXEIRA, M. A. Democracia e escândalos políticos. São Paulo em perspectiva, São Paulo, v. $15, \mathrm{n}^{\circ} 4$, p. 62-75, 2001.

DAWSON, Richard; PREWITT, Kenneth. Political Socialization. Little, Brown \& Company, 1969.

EASTON, David; DENNIS, Jack. Children in political system: origins of political legitimacy. New York: McGraw-Hill, 1969.

EMPRESA Brasileira de Comunicação. Agencia Brasil. Disponível em: $<$ http://agenciabrasil.ebc.com.br/justica/noticia/2019-03/lava-jato-completa-cinco-anos-com-155-pessoascondenadas>. Acesso em: 9 mai. 2019.

EKSTRÖM, Mats; JOHANSSON, Bengt. Talk scandals. Media, Culture\&Society, v. 30, n. 1, p. 61-79, 2008.

FERES JUNIOR, JOÃO; SASSARA, LUNA DE OLIVEIRA. Corrupção, escândalos e a cobertura midiática da política. Novos estud. CEBRAP, São Paulo, v. 35, n. 2, p. 205-225, 2016.

FILGUEIRAS, Fernando. A tolerância à corrupção no Brasil: uma antinomia entre normas morais e prática social. Opinião Pública, Campinas, v. 15, n. 2, p.386-421, novembro, 2009.

FILGUEIRAS, Fernando. Notas Críticas sobre o Conceito de Corrupção. Revista de Informação Legislativa, v.41, p.125-148, 2004.

HESS, Robert; TORNEY, Judith. The development of political attitudes in children. Garden City, NY: Doubleday. 1967.

HYMAN, Herbert. Political socialization. New York: Free Press, 1959. 
Campos Neutrais - Revista Latino-Americana de Relações Internacionais

Vol. 1, No 3, p. 88-106, Setembro- Dezembro de 2019

JENNINGS, M. Kent; NIEMI, Richard. The Political Character of Adolescents. Princeton: Princeton University Press. 1974.

KEIL, Ivete. Dos jovens contestadores aos jovens de hoje: uma nova forma de participação na pólis? In:

BAQUERO, Marcello (org.). Democracia, juventude e capital social no Brasil. Porto Alegre: Ed. UFRGS, 2004.

KLITGAARD, Robert. 1994. A Corrupção sob Controle. Rio de Janeiro: Jorge Zahar.

LATTMAN-WELTMAN, Fernando. Mídia e transição democrática: a (des)institucionalização do pan-óptico no Brasil. In.: LATTMAN-WELTMAN, F.; Abreu, A.; KORNIS, M. Mídia e política no Brasil: Jornalismo e ficção. Editora FGV, Rio de Janeiro, 2003.

LUCAS, João Ignácio Pires. Juventude e antipolítica no Brasil. Um estudo de cultura política e ideologia. 2003. Tese (Doutorado em Ciência Política) - Programa de Pós-Graduação em Ciência Política, Universidade Federal do Rio Grande do Sul, Porto Alegre, 2003.

MARKOVITS, Andrei S; SILVERSTEIN, Mark. (Ed.). The politics of scandal: Power and process in liberal democracies. New York: Holmes \& Meier, 1988.

MOISES, J. A. Os brasileiros e a democracia: bases sócio-políticas da legitimidade democrática. São Paulo. Editora Á tica, 1995.

MORAIS, Jennifer Azambuja de. Cultura Política e Capital Social: os efeitos do uso da internet na socialização de jovens no Sul do Brasil. Tese de doutorado. 286 f. 2017. PPG de Ciência Política da Universidade Federal do Rio Grande do Sul. 2017.

MINISTÉRIO Público Federal. Disponível em: <http://www.mpf.mp.br/para-o-cidadao/caso-lava-jato/atuacaona-1a-instancia/parana/linha-do-tempo>. Acesso em: 9 mai. 2019.

. Disponível em: <http://www.mpf.mp.br/para-o-cidadao/caso-lava-jato/entenda-o-caso>.

Acesso em: 9 mai. 2019.

NAZZARI, Rosana Kátia. Capital social e socialização política dos jovens no Brasil. EducaçãoUnisinos, v. 9, p. 145-154, 2005.

NIEMI, Richard; HEPBURN, Mary. The Rebirth of Political Socialization. Perspectives onPolitical Science, v. 24, p. 7-16, 1995. Disponível em <http://www.tandfonline.com/doi/abs/10.1080/10457097.1995.9941860>. Acesso em 17 jun. 2016.

NUPESAL. Núcleo de Pesquisa sobre a América Latina. Banco de dados: Democracia, mídias e capital social: Um estudo comparativo de socialização política dos jovens no Sul do Brasil (Porto Alegre, Florianópolis e Curitiba). 2015/2016. Paraná. 253 f. Tese (Doutorado em Ciência Política) - Instituto de Filosofia e Ciências Humanas, UFRGS, 2006. 
Campos Neutrais - Revista Latino-Americana de Relações Internacionais

Vol. 1, No 3, p. 88-106, Setembro- Dezembro de 2019

PERCHERON, Annick. La formation politique de l'individu. In: PARODI, J. L. La Politique. Paris: Hachette, 1971. p. $142-168$.

PIAGET, Jean. A tomada de consciência. São Paulo: Melhoramentos. 1977.

RIBEIRO, Renato J. A sociedade contra o social: o alto custo da vida pública no Brasil. São Paulo: Editora Schwarcz, 2000.

ROBALLO, José Henrique. Cultura política, socialização política e internet: um estudo de caso com os estudantes de ensino médio de Rio Pardo/RS. 2011. Dissertação (Mestrado). Programa de Pós-Graduação em Ciência Política, Universidade Federal do Rio Grande do Sul, Porto Alegre. 2011.

SCHMIDT, João Pedro. Juventude e Política no Brasil: a socialização política nos jovens na virada do milênio. Santa Cruz do Sul. EDUNISC. 2001.

SCHMIDT, João Pedro. Juventude e Política nos Anos 1990: Um estudo de socialização política no Brasil. 392 f. Tese (Doutorado). Instituto de Filosofia e Ciências Humanas, Universidade Federal do Rio Grande do Sul, 2000 .

SIGEL, Roberta (org.). Political Learning in adulthood: a sourcebook of theory and research.

Chicago/Londres: The University of Chicago Press, 1989.

SILVA, Marcos F. G. 2005. Corrupção e Produção de Bens Públicos. In: BIDERMAN, Ciro; ARVATE, Paulo, orgs. Economia do Setor Público no Brasil. Rio de Janeiro: Elsevier, pp. 126-135.

SILVEIRA, Angelita; AMORIM, Maria Salete. Socialização política e capital social: uma análise da participação da juventude no contexto escolar e político. Educação Unisinos, v. 9, n. 2, p. 155-163, 2005.

SPECK, Bruno. 2000. Mensurando a Corrupção: Uma Revisão de Dados Provenientes de Pesquisas Empíricas. Cadernos Adenauer 10 (1): 3-40.

THOMPSON, John B. O Escândalo político: poder e visibilidade na era da mídia. Petrópolis: EditoraVozes, 2002.

TUMBER, Howard; WAISBORD, Silvio R. (Ed.). Political scandals and media across democracies, Volume II. American Behavioral Scientist, Vol. 47 No. 9, 2004.

VYGOTSKY, Lev. A formação social da mente. Rio de Janeiro: Martins Fontes, 1996.

WARREN, Mark. 2005. La Democracia contra La Corrupción. Revista Mexica-na de Ciencias Políticas y Sociales 47 (193): 109-141. 